\title{
Predictive value of mucinous histology in colon cancer: a population-based, propensity score matched analysis
}

\author{
Rene Warschkow ${ }^{1,2,7}$, Ignazio Tarantino ${ }^{3,7}$, Felix J Huttner ${ }^{3}$, Bruno M Schmied ${ }^{1}$, Ulrich Guller ${ }^{4,5}$, \\ Markus K Diener ${ }^{3,6}$ and Alexis Ulrich ${ }^{\star, 3}$ \\ ${ }^{1}$ Department of Surgery, Kantonsspital St. Gallen, St. Gallen 9007, Switzerland; ${ }^{2}$ Institute of Medical Biometry and Informatics, \\ University of Heidelberg, Heidelberg 69120, Germany; ${ }^{3}$ Department of General, Visceral and Transplantation Surgery, University of \\ Heidelberg, Heidelberg 69120, Germany; ${ }^{4}$ Department of Medical Oncology and Hematology, Kantonsspital St. Gallen, St. Gallen \\ 9007, Switzerland; ${ }^{5}$ University Clinics for Visceral Surgery and Medicine, University Hospital Berne, Berne 3010, Switzerland and \\ ${ }^{6}$ Study Center of the German Surgical Society, University of Heidelberg, Heidelberg, Germany
}

Background: This investigation aimed to assess whether mucinous histology impacts overall (OS) and cancer-specific survival (CSS) in colon cancer.

Methods: Colon cancer patients who underwent surgery between 2004 and 2011 were identified in the Surveillance, Epidemiology, and End Results database. OS and CSS were assessed using Cox regression and propensity score methods.

Results: Out of 121628 patients, 12863 (10.6\%) had a mucinous histology. Five-year OS and CSS for mucinous adenocarcinoma were 54.4\% (95\% Cl: 53.4-55.5\%) and 66.5\% (95\% Cl: 65.5-67.5\%) compared with 60.2\% (95\% Cl: 59.8-60.5\%) and 71.9\% (95\% Cl: 71.5-72.2\%) for non-mucinous adenocarcinoma $(P<0.001)$. This survival disadvantage disappeared in multivariable analyses (hazard ratio $(H R)=1.02,95 \% \mathrm{Cl}: 0.99-1.05, P=0.269$ and $\mathrm{HR}=1.03,95 \% \mathrm{Cl}: 0.99-1.06, P=0.169$ ), and after propensity score matching (OS: $\mathrm{HR}=0.99,95 \% \mathrm{Cl}: 0.93-1.04, P=0.606$ and $\mathrm{CSS}: \mathrm{HR}=0.99,95 \% \mathrm{Cl}: 0.92-1.06, P=0.783$ ).

Conclusions: In this population-based investigation, a mucinous histology did not negatively impact survival. Hence, the present study does not provide evidence to change treatment strategies in patients with mucinous adenocarcinoma of the colon.

\begin{abstract}
Among patients with colon cancer, $\sim 10-20 \%$ present with a mucinous adenocarcinoma (MAC) (Kang et al, 2005; Catalano et al, 2012; Hyngstrom et al, 2012; Benedix et al, 2013) defined as a tumour composed of more than $50 \%$ extracellular mucin (Jass and Sobin, 1989). Whereas some studies report a worse prognosis of colorectal MAC compared with non-mucinous adenocarcinoma (NMAC) (Verhulst et al, 2012; Kim et al, 2013; Vigano et al, 2014), others have not found a worse prognosis (Kang et al, 2005; Catalano et al, 2012; Gao et al, 2013; Hugen et al, 2013; Hogan et al, 2014). We have previously analysed the impact of a mucinous histology on the prognosis of rectal cancer and did not find an
\end{abstract}

impact of MAC vs NMAC on survival (Tarantino et al, 2015). Two studies demonstrated worse outcomes for mucinous rectal cancer but not for MAC of the colon (Du et al, 2004; Hyngstrom et al, 2012). Some authors have suggested a more aggressive surgical treatment, an increased use of systemic chemotherapy, and a more stringent follow-up for patients with MAC (Benedix et al, 2013; Kim et al, 2013; Lee et al, 2013). The objective of the present population-based analysis was to evaluate in a cohort of exclusively colon cancer patients whether mucinous histology represents an independent prognostic factor using Cox regression and propensity score matching for optimal adjustment.

\footnotetext{
*Correspondence: Professor A Ulrich; E-mail: alexis.ulrich@med.uni-heidelberg.de

${ }^{7}$ These authors contributed equally to this work.
} 


\section{METHODS}

The colorectal cancer part $(N=866626)$ of the November 2013 ASCI text data-version of the Surveillance, Epidemiology, and End Results (SEER) Program of the National Cancer Institute, covering $\sim 28 \%$ of cancer cases in the United States, was the source of present analysis (National Cancer Institute, 2014). Of 220269 colon cancer patients diagnosed between 2004 and 2011, 121628 met the inclusion criteria for the present study presented in Figure 1. These patients were grouped according to histology into patients with MAC and NMAC. NMAC were defined based on the third edition of the International Classification of Diseases for Oncology (ICD-O-3) histology codes 8140, 8144, 8210, 8211, 8221, $8261,8262,8263$ and MAC by the codes 8480 and 8481 .

The main outcomes were overall (OS) and cancer-specific survival (CSS) defined as time to event data as days from the diagnosis. For OS, patients alive at the end of follow-up were censored. For CSS, patients alive or dead due to other than cancerspecific causes were censored.

Statistical analyses were performed using the $\mathrm{R}$ software (www.r-project.org). MAC vs NMAC was assessed as a prognostic factor for OS and CCS in univariate Cox regression and with riskadjustment for baseline confounding variables (tumour location, tumour stage, T-stage, retrieved regional lymph nodes, grading, preoperative carcinoembryonic antigen, year, age, gender, ethnicity, and marital status) in a full Cox model. In addition, an exact weighted-propensity score matching analysis using the MatchIt $\mathrm{R}$ package was performed for optimal adjustment for the baseline confounding variables (Ho et al, 2011). Each patient in the two groups was matched to all possible patients in the other group with exactly the same values of all the covariates. MAC patients that did not have a counterpart among the NMAC patients and vice versa were excluded from this analysis. The prognostic value of

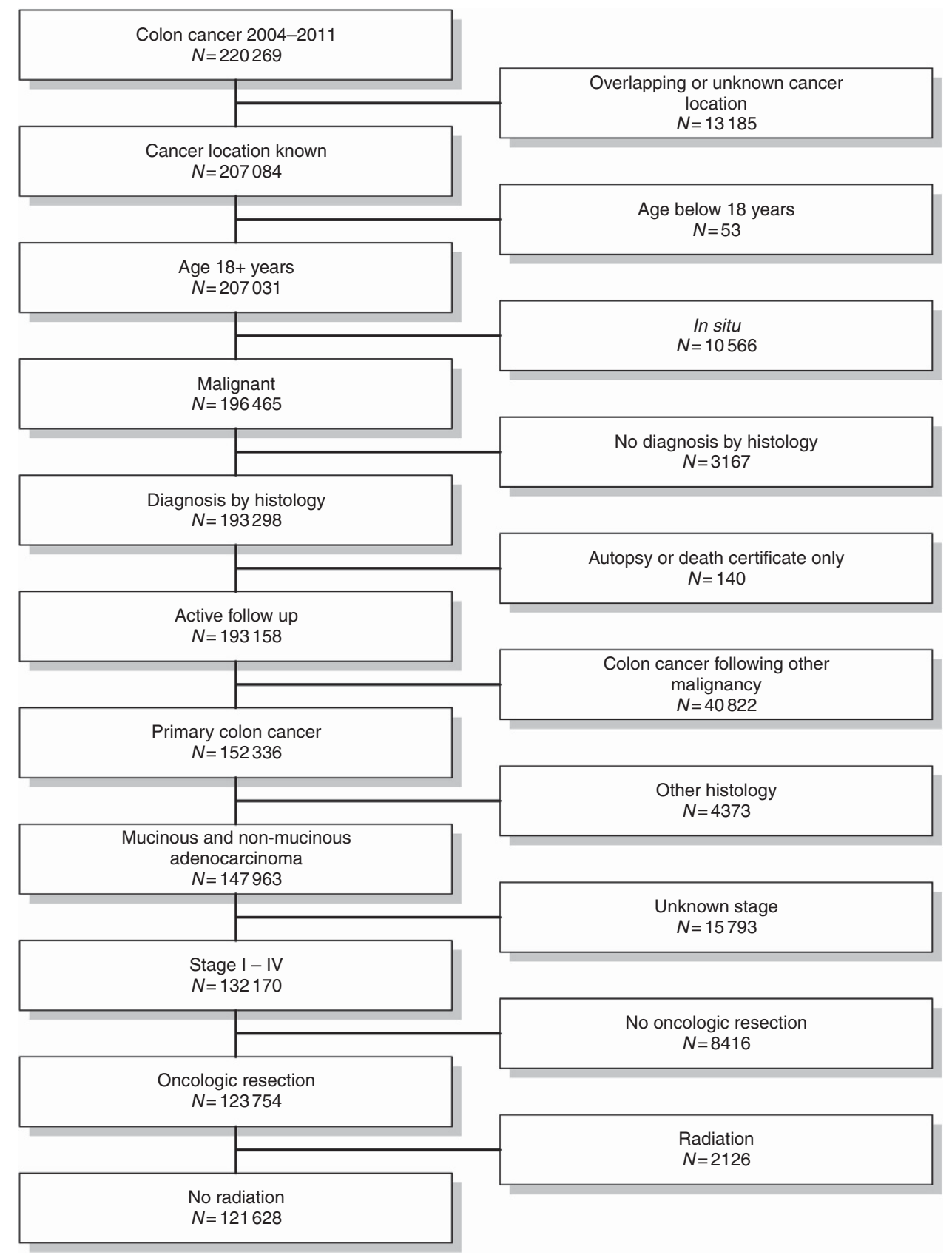

Figure 1. Flow chart of the patient cohort selection. 
mucinous vs non-mucinous histology for survival was then assessed in an additional Cox regression, incorporating the weights and strata obtained by the propensity score analysis.

\section{RESULTS}

Among 121628 patients diagnosed with stage I-IV adenocarcinoma, 12863 patients (10.6\%) had a MAC. Their histology was coded as mucinous adenocarcinoma $(N=10.492)$ and mucinproducing adenocarcinoma $(N=2.371)$ in the Surveillance, Epidemiology, and End Results database. The histology of the 108765 NMAC were coded as adenocarcinoma, not otherwise stated $(N=88.328)$, adenocarcinoma in tubulovillous adenoma $(N=9.213$, adenocarcinoma in adenomatous polyp $(N=7.853)$, adenocarcinoma in villous adenoma $(N=3.194)$, villous adenocarcinoma $(N=96)$, tubular adenocarcinoma $(N=64)$, and adenocarcinoma of intestinal type $(N=17)$. The mean follow-up was $35.4 \pm 27.1$ months. At the end of follow-up, 81692 patients $(67.2 \%)$ were alive, 26452 patients $(21.7 \%)$ died from cancer and 13484 (11.1\%) died of other causes.

MAC were associated with older age, right-sided location, more advanced stages, T4 tumours, resection of 12 or more lymph nodes, poor differentiation (G3 and G4), elevated carcinoembryonic antigen, female gender, and Caucasian ethnicity (Table 1). In univariate Cox regression, the overall mortality risk in patients with MAC was increased by $21 \%$ (hazard ratio $(\mathrm{HR})=1.21,95 \%$ CI: $1.18-1.25, P<0.001)$, and the risk for cancer-specific mortality by $26 \%(\mathrm{HR}=1.26,95 \% \mathrm{CI}: 1.22-1.31, P<0.001)$. The 5 -year OS in patients with MAC was 54.4\% (95\% CI: 53.4-55.5\%) compared with $60.2 \%$ (95\% CI: 59.8-60.5\%) in patients with a NMAC $(P<0.001)$. The 5 -year CSS in patients with a MAC was $66.5 \%$ (95\% CI: 65.5-67.5\%) compared with 71.9\% (95\% CI: 71.5-72.2\%) in patients with a NMAC $(P<0.001)$. In multivariable Cox regression, mucinous histology was not confirmed to have a significant negative effect on OS (HR $=1.02,95 \% \mathrm{CI}: 0.99-1.05$, $P=0.269)$ and CCS $(\mathrm{HR}=1.03,95 \% \mathrm{CI}: 0.99-1.06, P=0.169)$ (Table 2).

In the propensity score-based analysis, 6294 patients with a MAC were compared with 18350 patients with a NMAC without any significant differences in the baseline confounding variables persisting after propensity score matching $(P=1.000$ for all covariates). After propensity score matching, mucinous histology had no prognostic value for OS $(\mathrm{HR}=0.99,95 \% \mathrm{CI}$ : $0.93-1.04$, $P=0.606)$ and CSS (HR $=0.99,95 \% \mathrm{CI}: 0.92-1.06, P=0.783)$. The 5 -year OS in patients with a MAC was 59.8\% (95\% CI: 58.4-61.1\%) compared with $59.3 \%$ (95\% CI: 58.5-60.2\%) in patients with a NMAC. The 5-year CCS in patients with MAC was $73.4 \%(95 \% \mathrm{CI}$ : $72.2-74.7 \%$ ) compared with $73.2 \%$ (95\% CI: $72.4-74.0 \%)$ in patients with a NMAC.

\section{DISCUSSION}

To our knowledge, this is the first population-based analysis investigating the prognostic relevance of a mucinous histology in a large cohort of exclusively colon cancer patients adjusting with propensity score matching and multivariate analysis. The present investigation yields two main findings. First, MAC is associated with a variety of factors, such as a younger age of onset, location in the proximal colon, more advanced stage at presentation and poor grade of differentiation. Hence, the patient characteristics are strongly biased when comparing MAC vs NMAC. Second, after optimal adjustment for this bias, mucinous histology did not impact OS or CSS neither in multivariable Cox regression nor in propensity score-adjusted analyses. In consequence, the observed association between mucinous histology and worse OS and CSS in the univariate analysis is caused by differences in other clinical characteristics, such as tumour stage, grade, and localisation of the carcinoma, rather than the mucinous histology itself.

These findings are supported by several previous studies (Kang et al, 2005; Catalano et al, 2012; Hyngstrom et al, 2012; Hugen et al, 2013). One possible explanation for a worse prognosis of colorectal MAC in other studies (Verhulst et al, 2012; Kim et al, 2013; Vigano et al, 2014) might be an inadequate differentiation between signet ring carcinoma and MAC (Benedix et al, 2013). The inclusion of rectal and colon cancer patients into the same analysis might have contributed to the controversy, as some recent investigations have demonstrated a worse outcome for MAC of the rectum but not for MAC of the colon ( $\mathrm{Du}$ et al, 2004; Hyngstrom et al, 2012). However, in an analogous analysis of rectal instead of colon cancer by our research group similar results were obtained (Tarantino et al, 2015). Mucinous histology was associated with unfavourable tumour characteristics. When optimally adjusting for confounding variables, mucinous histology had no impact on OS and CSS. OS and CSS of colon $v s$ rectal cancer was worse for both NMAC $(\mathrm{HR}=1.31, P<0.001$ and $\mathrm{HR}=1.22, \quad P<0.001)$ and MAC $(\mathrm{HR}=1.17, \quad P<0.001$ and $\mathrm{HR}=1.09, P=0.040$ ) in Cox regression analyses.

Moreover, the incidence of MAC differs substantially among different geographical regions (Du et al, 2004; Catalano et al, 2012). In addition, based on molecular analysis and clinical behaviour, two subtypes of MAC (microsatellite stable vs microsatellite instable) have been postulated and lead to the hypothesis that a different distribution of these two subtypes might have influenced the results especially in smaller series (Kondo et al, 2002; Liu et al, 2004; Leopoldo et al, 2008; Catalano et al, 2012).

The clinical relevance of identifying risk factors associated with an adverse outcome in patients with colorectal cancer is highlighted by patients diagnosed with stage II disease. Whereas, the survival benefit of adjuvant chemotherapy in stage III colon cancer has been well established, the value of such treatment for stage II colon cancer remains controversial (Haller et al, 2005; Twelves et al, 2005; Quasar Collaborative Group et al, 2007; Andre et al, 2009). In this regard, it is of utmost importance to identify those patients who will most likely benefit from adjuvant treatment. Based on previous studies demonstrating a worse prognosis of colorectal MAC, a more aggressive oncological treatment has been suggested, especially for patients with stage II disease (Lee et al, 2013). In contrast, a mucinous histology is not included in the list of risk factors on which to base adjuvant treatment (Benson et al, 2004). The present investigation, in which a mucinous histology per se was not identified as an independent negative prognostic factor, supports the existing guidelines. Furthermore, recent studies showed no differences in the efficacy of adjuvant chemotherapy between patients with MAC and NMAC (Catalano et al, 2012; Hugen et al, 2013). Hence, current adjuvant treatment recommendations should be applied regardless of a mucinous histology in colon cancer.

We would like to acknowledge the limitations of the present investigation: data on chemotherapeutic treatments, family history, comorbidities, performance status and molecular data such as microsatellite instability are not available in the Surveillance, Epidemiology, and End Results database. In addition, although definitions of mucinous and signet ring cell histology have been standardised, variation in interpretation may have resulted in misclassification. Despite these limitations, the present study has a variety of strengths. First, the population-based nature of the registry is associated with a high degree of generalisability. Second, this study reports data over an 8-year period and includes 121628 patients with stage I-IV colon cancer, of whom 12863 (10.6\%) patients had a MAC. The large sample size is associated with a high degree of power. Third, the results of multivariable analysis were 
Table 1. Patient characteristics

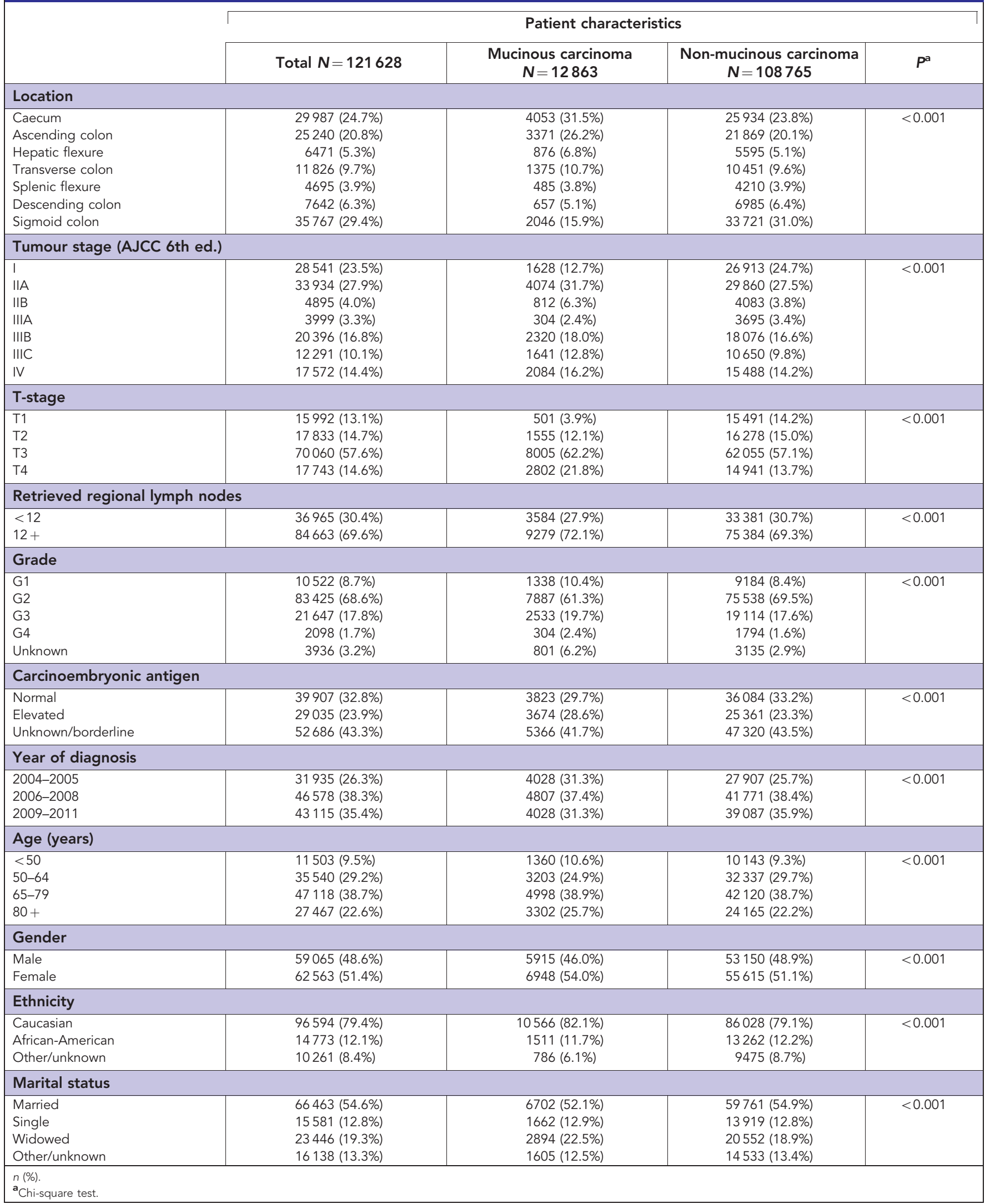

confirmed after propensity score matching. The importance in matching all patients' characteristics is highlighted when considering the difference in the grading of the MAC and NMAC, as patients with a MAC were more often diagnosed with a poor grade of differentiation. In this respect, previous studies accounted only for differences in tumour stage. 
Table 2. Prognostic factors for overall and cancer-specific mortality

\begin{tabular}{|c|c|c|c|c|c|c|c|c|}
\hline & \multicolumn{4}{|c|}{ Overall survival using Cox regression } & \multicolumn{4}{|c|}{ Cancer-specific survival using Cox regression } \\
\hline & \multicolumn{2}{|c|}{ Univariate $^{a}$} & \multicolumn{2}{|c|}{ Full model ${ }^{b}$} & \multicolumn{2}{|c|}{ Univariate $^{a}$} & \multicolumn{2}{|c|}{ Full model ${ }^{b}$} \\
\hline & $\mathrm{HR}(95 \% \mathrm{Cl})$ & $P^{c}$ & $\mathrm{HR}(95 \% \mathrm{Cl})$ & $P^{c}$ & $\mathrm{HR}(95 \% \mathrm{Cl})$ & $P^{c}$ & $\mathrm{HR}(95 \% \mathrm{Cl})$ & $P^{c}$ \\
\hline $\begin{array}{l}\text { Non-mucinous } \\
\text { Mucinous }\end{array}$ & $\begin{array}{c}\text { Reference } \\
1.21(1.18-1.25)\end{array}$ & $<0.001$ & $\begin{array}{c}\text { Reference } \\
1.02(0.99-1.05)\end{array}$ & 0.269 & $\begin{array}{c}\text { Reference } \\
1.26(1.22-1.31)\end{array}$ & $<0.001$ & $\begin{array}{c}\text { Reference } \\
1.03(0.99-1.06)\end{array}$ & 0.169 \\
\hline \multicolumn{9}{|l|}{ Location } \\
\hline \multicolumn{9}{|c|}{ Tumour stage (AJCC 6th ed.) } \\
\hline \multicolumn{9}{|l|}{ T-stage } \\
\hline $\begin{array}{l}\mathrm{T} 1 \\
\text { T2 } \\
\text { T3 } \\
\text { T4 }\end{array}$ & $\begin{array}{c}\text { Reference } \\
1.51(1.43-1.59) \\
2.80(2.68-2.92) \\
6.06(5.79-6.35)\end{array}$ & $<0.001$ & $\begin{array}{c}\text { Reference } \\
1.29(1.22-1.36) \\
1.67(1.52-1.84) \\
2.43(2.20-2.67)\end{array}$ & $<0.001$ & $\begin{array}{c}\text { Reference } \\
1.87(1.71-2.06) \\
6.24(5.78-6.74) \\
16.7(15.5-18.1)\end{array}$ & $<0.001$ & $\begin{array}{c}\text { Reference } \\
1.44(1.31-1.59) \\
1.96(1.73-2.21) \\
2.95(2.60-3.33)\end{array}$ & $<0.001$ \\
\hline \multicolumn{9}{|c|}{ Retrieved regional lymph nodes } \\
\hline $\begin{array}{l}<12 \\
12+\end{array}$ & $\begin{array}{c}\text { Reference } \\
0.78(0.77-0.80) \\
\end{array}$ & $<0.001$ & $\begin{array}{c}\text { Reference } \\
0.74(0.72-0.75) \\
\end{array}$ & $<0.001$ & $\begin{array}{c}\text { Reference } \\
0.80(0.78-0.82) \\
\end{array}$ & $<0.001$ & $\begin{array}{c}\text { Reference } \\
0.72(0.70-0.74) \\
\end{array}$ & $<0.001$ \\
\hline \multicolumn{9}{|l|}{ Grade } \\
\hline \multicolumn{9}{|l|}{ Year of diagnosis } \\
\hline $\begin{array}{l}2004-2005 \\
2006-2008 \\
2009-2011\end{array}$ & $\begin{array}{c}\text { Reference } \\
0.94(0.92-0.96) \\
0.86(0.84-0.89)\end{array}$ & $<0.001$ & $\begin{array}{c}\text { Reference } \\
1.00(0.98-1.02) \\
0.96(0.93-0.99)\end{array}$ & 0.004 & $\begin{array}{c}\text { Reference } \\
0.94(0.91-0.96) \\
0.86(0.83-0.90)\end{array}$ & $<0.001$ & $\begin{array}{c}\text { Reference } \\
1.01(0.98-1.03) \\
0.95(0.91-0.98)\end{array}$ & 0.002 \\
\hline \multicolumn{9}{|l|}{ Age (years) } \\
\hline $\begin{array}{l}<50 \\
50-64 \\
65-79 \\
80+\end{array}$ & $\begin{array}{c}\text { Reference } \\
0.99(0.95-1.03) \\
1.44(1.38-1.50) \\
2.84(2.73-2.96) \\
\end{array}$ & $<0.001$ & $\begin{array}{c}\text { Reference } \\
1.14(1.09-1.19) \\
1.88(1.80-1.96) \\
3.87(3.71-4.05) \\
\end{array}$ & $<0.001$ & $\begin{array}{c}\text { Reference } \\
0.89(0.84-0.93) \\
1.04(0.99-1.08) \\
1.67(1.59-1.74)\end{array}$ & $<0.001$ & $\begin{array}{c}\text { Reference } \\
1.08(1.03-1.13) \\
1.52(1.45-1.60) \\
2.71(2.58-2.85)\end{array}$ & $<0.001$ \\
\hline \multicolumn{9}{|l|}{ Gender } \\
\hline $\begin{array}{l}\text { Male } \\
\text { Female }\end{array}$ & $\begin{array}{c}\text { Reference } \\
1.00(0.98-1.02) \\
\end{array}$ & 0.992 & $\begin{array}{c}\text { Reference } \\
0.81(0.79-0.82) \\
\end{array}$ & $<0.001$ & $\begin{array}{c}\text { Reference } \\
1.03(1.01-1.06) \\
\end{array}$ & 0.011 & $\begin{array}{c}\text { Reference } \\
0.89(0.87-0.91) \\
\end{array}$ & $<0.001$ \\
\hline \multicolumn{9}{|l|}{ Ethnicity } \\
\hline $\begin{array}{l}\text { Caucasian } \\
\text { African-American } \\
\text { Other/unknown }\end{array}$ & $\begin{array}{c}\text { Reference } \\
1.13(1.09-1.16) \\
0.78(0.75-0.81)\end{array}$ & $<0.001$ & $\begin{array}{c}\text { Reference } \\
1.18(1.14-1.21) \\
0.82(0.79-0.86)\end{array}$ & $<0.001$ & $\begin{array}{c}\text { Reference } \\
1.25(1.21-1.29) \\
0.86(0.82-0.90)\end{array}$ & $<0.001$ & $\begin{array}{c}\text { Reference } \\
1.20(1.16-1.24) \\
0.86(0.82-0.90)\end{array}$ & $<0.001$ \\
\hline \multicolumn{9}{|l|}{ Marital status } \\
\hline $\begin{array}{l}\text { Married } \\
\text { Single } \\
\text { Widowed } \\
\text { Other/unknown }\end{array}$ & $\begin{array}{c}\text { Reference } \\
1.32(1.28-1.36) \\
1.85(1.81-1.89) \\
1.20(1.16-1.24) \\
\end{array}$ & $<0.001$ & $\begin{array}{c}\text { Reference } \\
1.34(1.30-1.38) \\
1.35(1.32-1.39) \\
1.22(1.18-1.26) \\
\end{array}$ & $<0.001$ & $\begin{array}{c}\text { Reference } \\
1.34(1.30-1.39) \\
1.54(1.50-1.59) \\
1.16(1.12-1.21) \\
\end{array}$ & $<0.001$ & $\begin{array}{c}\text { Reference } \\
1.26(1.22-1.31) \\
1.27(1.23-1.32) \\
1.15(1.10-1.19) \\
\end{array}$ & $<0.001$ \\
\hline \multicolumn{9}{|c|}{ 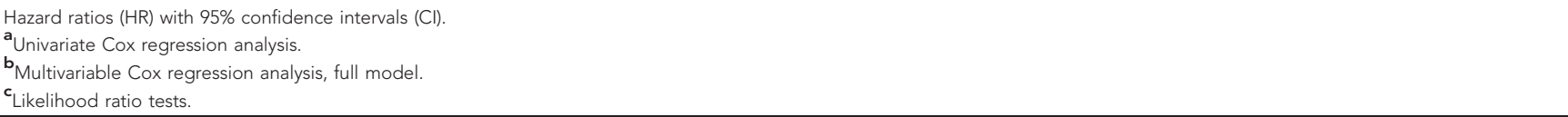 } \\
\hline
\end{tabular}


In conclusion, the present population-based investigation on exclusively colon cancer patients did not provide evidence that a mucinous histology itself deteriorates OS or CSS. Therefore, a mucinous histology cannot be considered as an independent risk factor upon which the decision for or against chemotherapy should be based. Standard treatment strategies applied in patients with NMAC of the colon can also be applied in patients with MAC of the colon in accordance with recent guidelines.

\section{CONFLICT OF INTEREST}

The authors declare no conflict of interest.

\section{REFERENCES}

Andre T, Boni C, Navarro M, Tabernero J, Hickish T, Topham C, Bonetti A, Clingan P, Bridgewater J, Rivera F, de Gramont A (2009) Improved overall survival with oxaliplatin, fluorouracil, and leucovorin as adjuvant treatment in stage II or III colon cancer in the MOSAIC trial. J Clin Oncol 27: 3109-3116.

Benedix F, Kuester D, Meyer F, Lippert H (2013) Influence of mucinous and signet-ring cell differentiation on epidemiological, histological, molecular biological features, and outcome in patients with colorectal carcinoma. Zentralbl Chir 138: 427-433.

Benson 3rd AB, Schrag D, Somerfield MR, Cohen AM, Figueredo AT, Flynn PJ, Krzyzanowska MK, Maroun J, McAllister P, Van Cutsem E, Brouwers M, Charette M, Haller DG (2004) American Society of Clinical Oncology recommendations on adjuvant chemotherapy for stage II colon cancer. J Clin Oncol 22: 3408-3419.

Catalano V, Loupakis F, Graziano F, Bisonni R, Torresi U, Vincenzi B, Mari D, Giordani P, Alessandroni P, Salvatore L, Fornaro L, Santini D, Baldelli AM, Rossi D, Giustini L, Silva RR, Falcone A, D’Emidio S, Rocchi M, Luzi Fedeli S (2012) Prognosis of mucinous histology for patients with radically resected stage II and III colon cancer. Ann Oncol 23: 135-141.

Du W, Mah JT, Lee J, Sankila R, Sankaranarayanan R, Chia KS (2004) Incidence and survival of mucinous adenocarcinoma of the colorectum: a population-based study from an Asian country. Dis Colon Rectum 47: 78-85.

Gao P, Song YX, Xu YY, Sun Z, Sun JX, Xu HM, Wang ZN (2013) Does the prognosis of colorectal mucinous carcinoma depend upon the primary tumour site? Results from two independent databases. Histopathology 63: 603-615.

Haller DG, Catalano PJ, Macdonald JS, O’Rourke MA, Frontiera MS, Jackson DV, Mayer RJ (2005) Phase III study of fluorouracil, leucovorin, and levamisole in high-risk stage II and III colon cancer: final report of Intergroup 0089. J Clin Oncol 23: 8671-8678.

Ho DE, Imai K, King G, Elizabeth AS (2011) MatchIt: nonparametric preprocessing for parametric causal inference. J Stat Softw 42: 1-28.

Hogan J, Burke JP, Samaha G, Condon E, Waldron D, Faul P, Coffey JC (2014) Overall survival is improved in mucinous adenocarcinoma of the colon. Int J Colorectal Dis 29: 563-569.

Hugen N, Verhoeven RH, Radema SA, de Hingh IH, Pruijt JF, Nagtegaal ID, Lemmens VE, de Wilt JH (2013) Prognosis and value of adjuvant chemotherapy in stage III mucinous colorectal carcinoma. Ann Oncol 24: 2819-2824.
Hyngstrom JR, Hu CY, Xing Y, You YN, Feig BW, Skibber JM, Rodriguez-Bigas MA, Cormier JN, Chang GJ (2012) Clinicopathology and outcomes for mucinous and signet ring colorectal adenocarcinoma: analysis from the National Cancer Data Base. Ann Surg Oncol 19: 2814-2821.

Jass JR, Sobin LH (1989) International Histological Classification of Tumours: Histologic Typing of Intestinal Tumours vol. 15World Health Organization: Geneva 32-33.

Kang H, O’Connell JB, Maggard MA, Sack J, Ko CY (2005) A 10-year outcomes evaluation of mucinous and signet-ring cell carcinoma of the colon and rectum. Dis Colon Rectum 48: 1161-1168.

Kim SH, Shin SJ, Lee KY, Kim H, Kim TI, Kang DR, Hur H, Min BS, Kim NK, Chung HC, Roh JK, Ahn JB (2013) Prognostic value of mucinous histology depends on microsatellite instability status in patients with stage III colon cancer treated with adjuvant FOLFOX chemotherapy: a retrospective cohort study. Ann Surg Oncol 20: 3407-3413.

Kondo T, Masuda H, Abe Y, Takayama T (2002) Two subtypes in colorectal mucinous carcinoma in relation to microsatellite instability. Hepatogastroenterology 49: 660-663.

Lee DW, Han SW, Lee HJ, Rhee YY, Bae JM, Cho NY, Lee KH, Kim TY, Oh DY, Im SA, Bang YJ, Jeong SY, Park KJ, Park JG, Kang GH, Kim TY (2013) Prognostic implication of mucinous histology in colorectal cancer patients treated with adjuvant FOLFOX chemotherapy. $\mathrm{Br} J$ Cancer 108: 1978-1984.

Leopoldo S, Lorena B, Cinzia A, Gabriella DC, Angela Luciana B, Renato C, Antonio M, Carlo S, Cristina P, Stefano C, Maurizio T, Luigi R, Cesare B (2008) Two subtypes of mucinous adenocarcinoma of the colorectum: clinicopathological and genetic features. Ann Surg Oncol 15: 1429-1439.

Liu XP, Sato T, Oga A, Ikemoto K, Kawauchi S, Ikeda E, Sasaki K (2004) Two subtypes of mucinous colorectal carcinoma characterized by laser scanning cytometry and comparative genomic hybridization. Int J Oncol 25: 615-621.

National Cancer Institute (2014) Surveillance, Epidemiology, and End Results Program (SEER) Research Data (1973-2011) released April 2014, based on the November 2013 submission. Available at www.seer.cancer.gov (accessed 27 April, 2014).

Quasar Collaborative Group, Gray R, Barnwell J, McConkey C, Hills RK, Williams NS, Kerr DJ (2007) Adjuvant chemotherapy versus observation in patients with colorectal cancer: a randomised study. Lancet 370: 2020-2029.

Tarantino I, Huttner FJ, Warschkow R, Schmied BM, Diener MK, Ulrich A (2015) Prognostic relevance of mucinous subtype in a population-based propensity score analysis of 40083 rectal cancer patients. Ann Surg Oncol; e-pub ahead of print 29 December 2015; doi:10.1245/s10434-015-5029-7.

Twelves C, Wong A, Nowacki MP, Abt M, Burris 3rd H, Carrato A, Cassidy J, Cervantes A, Fagerberg J, Georgoulias V, Husseini F, Jodrell D, Koralewski P, Kroning H, Maroun J, Marschner N, McKendrick J, Pawlicki M, Rosso R, Schuller J, Seitz JF, Stabuc B, Tujakowski J, Van Hazel G, Zaluski J, Scheithauer W (2005) Capecitabine as adjuvant treatment for stage III colon cancer. N Engl J Med 352: 2696-2704.

Verhulst J, Ferdinande L, Demetter P, Ceelen W (2012) Mucinous subtype as prognostic factor in colorectal cancer: a systematic review and metaanalysis. J Clin Pathol 65: 381-388.

Vigano L, Russolillo N, Ferrero A, De Rosa G, Ferreri E, Forchino F, Sperti E, Capussotti L (2014) Resection of liver metastases from colorectal mucinous adenocarcinoma: is this a different disease? Results of a case-control study. Ann Surg 260: 878-884; Discussion 884-885. 